\title{
Dynamics of Defensive Reactivity in Patients with Panic Disorder and Agoraphobia: Implications for the Etiology of Panic Disorder
}

\author{
Jan Richter, Alfons O. Hamm, Christiane A. Pané-Farré, Alexander L. Gerlach, Andrew T. \\ Gloster, Hans-Ulrich Wittchen, Thomas Lang, Georg W. Alpers, Sylvia Helbig-Lang, Jürgen \\ Deckert, Thomas Fydrich, Lydia Fehm, Andreas Ströhle, Tilo Kircher, and Volker Arolt
}

Background: The learning perspective of panic disorder distinguishes between acute panic and anxious apprehension as distinct emotional states. Following animal models, these clinical entities reflect different stages of defensive reactivity depending upon the imminence of interoceptive or exteroceptive threat cues. The current study tested this model by investigating the dynamics of defensive reactivity in a large group of patients with panic disorder and agoraphobia (PD/AG).

Methods: Three hundred forty-five $\mathrm{PD} / \mathrm{AG}$ patients participated in a standardized behavioral avoidance test (being entrapped in a small, dark chamber for 10 minutes). Defense reactivity was assessed measuring avoidance and escape behavior, self-reports of anxiety and panic symptoms, autonomic arousal (heart rate and skin conductance), and potentiation of the startle reflex before and during exposure of the behavioral avoidance test.

Results: Panic disorder and agoraphobia patients differed substantially in their defensive reactivity. While $31.6 \%$ of the patients showed strong anxious apprehension during this task (as indexed by increased reports of anxiety, elevated physiological arousal, and startle potentiation), $20.9 \%$ of the patients escaped from the test chamber. Active escape was initiated at the peak of the autonomic surge accompanied by an inhibition of the startle response as predicted by the animal model. These physiological responses resembled the pattern observed during the 34 reported panic attacks.

Conclusions: We found evidence that defensive reactivity in $\mathrm{PD} / \mathrm{AG}$ patients is dynamically organized ranging from anxious apprehension to panic with increasing proximity of interoceptive threat. These data support the learning perspective of panic disorder.

Key Words: Agoraphobia, anxiety, fear, panic attacks, panic disorder, startle potentiation

Patients with panic disorder (PD) experience recurrent unexpected panic attacks and worry about future attacks and their injurious consequences. It has been suggested that these emotional states rapidly beginning brief episodes of intense fear to imminent threat and future oriented anxietytowardthe occurrence of nonpredictable aversive events are not only distinct clinical entities (1) but are also regulated by different neural networks.

Using potentiation of the startle response to measure fear and anxiety, Davis et al. (2) demonstrated in rodents that imminent fear-eliciting stimuli activate the basolateral amygdala, which projects to the central nucleus of the amygdala. The medial part of the central nucleus then serves as the main output relay producing rapid and short-acting fear or panic responses (2). Additionally, the lateral part of the central nucleus releases corticotropin-releasing hormone into the bed nucleus of the stria terminalis (BNST), eliciting the more slowly acting but longer lasting sustained anxiety response to an unsafe context. Accordingly, lesions of the central nucleus of the amygdala, but not the BNST, blocked fear-potentiated startle to short 
cues predicting painful shocks. In contrast, lesions of the BNST, but not the central nucleus, blocked potentiated startle in an unsafe context. Interestingly, PD patients do not show increased phasic fear to short cues predicting the occurrence of aversive events $(3,4)$ but do show stronger potentiation of the startle reflex in an unsafe context of unpredictable shocks (5). This suggests that patients might be particularly vulnerable to unsecure environments, comparable with the pre-encounter defense described in the predator-imminence model $(6,7)$.

According to this model, defensive behavior is dynamically organized depending upon the proximity of the threat. At the first stage when the organism is in a context where a predator has been encountered previously but has not yet been detected (pre-encounter defense), preemptive behavior, including threat-nonspecific vigilance, is engaged. As soon as the predator is identified (postencounter), the organism freezes and increased selective attention is allocated to the potential threat. Circa strike defense, characterized by strong autonomic arousal and escape behavior, is activated when the threat is imminent.

This model is in line with several tenants of the learning perspective on the etiology of PD $(1,8)$. According to this perspective, initial attacks, defined as a sense of extreme fear of dying or of losing control accompanied by a massive autonomic surge and flight tendencies, a typical circa strike defense behavior, set the stage for the development of PD. By associating exteroceptive and interoceptive cues that are present during the first panic attack with the upcoming danger of further full-blown panic attacks, patients not only become hypervigilant toward somatic symptoms (pre-encounter defense) but also develop anxious apprehension when subtle body symptoms are identified (postencounter defense). Supporting this notion, individuals who report high trait fear of somatic symptoms, i.e., a risk marker for PD, show increased potentiation of their startle response when weak interoceptive cues are identified after recovery from a hyperventilation challenge (9).

In the current study, we tested this theoretical perspective by investigating the dynamics of defensive behavior in a large sample of patients meeting DSM-IV (text revision) criteria of panic disorder and agoraphobia (PD/AG). Agoraphobic fear and avoidance refer to situations where it is difficult to escape and where panic attacks might occur, clustering around situations entailing some degree of entrapment like tunnels, elevators, crowded areas, public transportation, or being in the backseat of a car. Interestingly, such fears of restriction and avoidance of entrapment are also main symptoms of claustrophobia (10). Indeed, patients with PD/AG regularly show high comorbidity with claustrophobia (11) and also have clinical features in common: both groups fear and try to avoid interoceptive stimuli $(12,13)$ and suffer from uncued panic attacks $(11,14)$. To study the dynamics of defensive reactivity in patients with $\mathrm{PD} / \mathrm{AG}$, we used a standardized behavioral avoidance test (BAT) (exposure to a small, dark, and closed chamber) that has successfully been used previously to investigate fear response patterns in claustrophobia (15). In addition, this BAT is very much comparable with the paradigms used in animal research to study anxious apprehension (e.g., light enhanced startle or open field paradigms), thus enabling translation from animal findings to human clinical anxiety.

To assess defensive reactivity in patients with $\mathrm{PD} / \mathrm{AG}$, we measured autonomic arousal (heart rate and skin conductance), flight behavior (as indexed by premature termination of the exposure period), experience of anxious apprehension (measured before the onset of the task), experience of panic during the task (marked by pressing a panic button), and modulation of the startle reflex as an index of amygdala-dependent defense system activation $(2,16)$. The modulation of the startle response seems to be a specifically interesting measure in this 
context because recent evidence suggests that the startle reflex is markedly inhibited during the imminent stage of threat (17).

We hypothesized that being locked in a confined dark chamber would elicit a range of defensive reactivity varying from anxious apprehension to active escape or complete avoidance in many, but probably not all, patients with PD/AG. Moreover, according to the learning perspective of the etiology of PD (1), anxious apprehension during such challenge should provoke panic attacks. Therefore, we expected that the probability for the occurrence of panic attacks would be increased in this context, providing the opportunity to monitor defensive reactivity during panic attacks. Finally, we expected that during imminent threat, such as an acute panic attack or active flight behavior (i.e., escape from the chamber), autonomic arousal would increase and would be associated with a relative inhibition of the startle reflex, while the same defensive reflex would be potentiated during anxious apprehension.

\section{Methods and Materials}

\section{Participants}

Three hundred forty-five patients (259 female patients) of an overall total of 369 patients $(18)^{1}$ with a principal diagnosis of panic disorder with agoraphobia and enrolled for the multicenter randomized controlled clinical trial study Mechanism of Action in Cognitive Behavioral Therapy (CBT) participated in the study. Patient recruitment and inclusion and exclusion criteria of the overarching clinical trial, as well as patients' sociodemographic characteristics and comorbid diagnoses, are described elsewhere $(18,19)$. Diagnosis of PD/AG was established by a standardized computer-administered face-to-face Computer Assisted Personal Interview-World Health Organization-Composite International Diagnostic Interview (CAPI-WHO-CIDI) by trained and certified interviewers (20) (see Supplement 1 for reliability of the diagnosis). Mean age of the patients at assessment was 35.26 years, $\mathrm{SD}=$ 10.71. All patients were Caucasian and free from psychotropic medication. Patients gave written informed consent after receiving a detailed description of the study. The study was approved by the Ethics Committee of the Medical Faculty of the Technical University of Dresden, which was valid for all participating centers.

\section{Experimental Stimuli and Procedure}

Following inclusion of the patients, severity of psychopathology was evaluated during baseline assessment using several questionnaires (18). Patients participated in the BAT in each of the eight participating centers ${ }^{2}$ following baseline assessment and before treatment. The BAT consisted of a standardized exposure to a small $(75 \mathrm{~cm}$ wide, $120 \mathrm{~cm}$ long, $190 \mathrm{~cm}$ high), dark and closed test chamber constructed according to the descriptions by Öst et al. (15). All assessment personnel were trained to adhere to a written study manual. After explaining the procedure and attaching the sensors for recording of the physiological signals, the BAT commenced with an anticipation period, during which patients were facing the test

\footnotetext{
${ }^{1}$ Three hundred sixty-nine patients were included in the randomized controlled clinical trial. Nineteen patients who were allocated to the wait-list control group were re-randomized to one of the active treatment conditions following the wait-list period. Since these patients already completed the BAT at their first allocation to the waitlist control condition, we had only data from initial BAT assessments from 350 patients. Five patients did not participate in the BAT due to organizational problems.

${ }^{2}$ Aachen, Berlin-Adlershof, Berlin-Charité, Bremen, Dresden, Greifswald, Münster, and Würzburg.
} 
chamber with its door open while sitting for 10 minutes. Then, patients were instructed to enter the test chamber and take a seat and the door was locked from outside by the experimenter. Patients were instructed to sit quietly in the chamber for as long as possible and to knock on the door if they wanted to leave the chamber before the maximum time elapsed (10 minutes; see Supplement 1 for exact instruction). All patients complied with these instructions as documented by the assessors. After exposure, patients were again seated in front of the opened chamber for an 8-minute recovery period. Patients were unaware of the maximum duration of each period. Intensity of experienced anxiety and panic symptoms were assessed by paper and pencil immediately after each period on a 10-point Likert scale ranging from 1 (not at all) to 10 (very strong). Patients were instructed to press a button whenever they experienced a panic attack. The output of the button press was digitized by an analog to digital (A/D) converter (Scientific Solutions, Mentor, Ohio) and recorded as a separate channel with the VPM software (21).

A digitized 50-msec burst of white noise ( $105 \mathrm{dBA}$, rise/fall time $<1 \mathrm{msec}$ ) generated by the sound tool box of VPM was amplified by a recording mixer (Omintronic RS-602, Waldbüttelbrunn, Germany) and presented binaurally through headphones (AKG K66, Vienna, Austria) to serve as startle-eliciting stimulus. A continuous $60 \mathrm{dBA}$ background noise was generated by the recording mixer. Thirty acoustic startle probes were presented (three probes per minute with a randomized interstimulus interval (varying between $10 \mathrm{sec}$ and 30 sec) during anticipation and exposure. Nine startle probes were presented during the last 3 minutes of the recovery period.

\section{Experimental Control and Data Collection}

A personal computer running VPM (22) controlled stimulus presentation and data acquisition. Bioamplifiers recorded electromyographic activity over the orbicularis oculi, skin conductance level (SCL), and electrocardiogram as reported elsewhere (23).

\section{Data Reduction and Analysis}

The reflex eyeblink data were reduced and scored offline using a computer program that identified the peak amplitude (in microvolts; for details of the scoring procedure, see Limberg et al. [23] and Supplement 1).

Skin conductance level (in $\mu \mathrm{S}$ ) and electrocardiogram R-R intervals (converted to beats per minute) were reduced into half-second bins and averaged across blocks of 10 seconds, excluding the 7 seconds after delivery of the startle probes.

As will be elaborated below, patients were grouped according to their defensive behavior in the BAT or lack thereof into anxious completers, escapers, avoiders, or nonanxious completers. To evaluate potential differences between these groups, univariate analyses of variance with group as a between-subjects variable and phase (anticipation vs. exposure vs. recovery) (and in the case of physiological data, time [ten 1-minute blocks]) as within-subject variables were conducted for all dependent variables. All statistical tests used a significance level of $p<.05$. Greenhouse-Geisser corrections of degrees of freedom were applied whenever appropriate. 


\section{Results}

\section{Behavioral Data}

Thirty-nine patients $(11.3 \%)$ refused to participate in the BAT entirely or refused to enter the chamber after the anticipation period and were therefore classified as avoiders. Seventy-two patients $(20.9 \%)$ entered the test chamber after completion of the anticipation period but did not finish the exposure and were therefore classified as escapers. The exposure duration in this group varied between 3 and 580 seconds (mean $=225.64$; $\mathrm{SD}=170.96$ ). Two hundred thirty-four patients remained in the test chamber for the entire 10 minutes of the exposure period and were classified as completers. Within this group, 109 patients (31.6\%) reported only minimal or no anxiety during the exposure (anxiety ratings $\leq 3$ ); thus, these patients served as a nonanxious control group (nonanxious completers) because the BAT was obviously not a challenge for these patients. One hundred twenty-five patients $(36.2 \%)$ completed the exposure test despite medium to high levels of anxiety (anxious completers). Table 1 shows the gender distribution, age, and severity of $\mathrm{PD} / \mathrm{AG}$, depressive, and claustrophobic symptoms. Gender distribution differed significantly between groups with a higher proportion of female patients in the avoider and escaper compared with both completer groups. Moreover, compared with the nonanxious completers, all other patients were characterized by significantly more severe panic/anxiety and depressive symptoms both according to clinical interview and self-report data. Avoiders and escapers reported significantly more claustrophobic fear than anxious completers who reported significantly higher claustrophobic fear than nonanxious completers.

\section{Anticipation Period}

During anticipation, avoiders, escapers, and anxious completers reported more anxiety and more intense panic and showed higher heart rates (HR) and SCL than nonanxious completers. No significant group differences occurred for startle response magnitudes. Means, SD, and significant group differences in reported anxiety and defensive reactivity for the four groups during anticipation, exposure, and recovery are presented in Table 2. Physiological measures decreased throughout anticipation revealing an overall adaptation to the experimental situation [HR: time $\mathrm{F}(9,2475)=12.91, \eta^{2}=.05$; SCL: time $\mathrm{F}(9,2574)=29.98, \eta^{2}=.10$; startle: time $F(9,1872)=49.17, \eta^{2}=.19$; all ps $\left.<.001\right]$, which did not differ for the four groups (see Figure S1 in Supplement 1 for the time course of the physiological responses).

\section{Exposure Period}

Anxious Versus Nonanxious Completers. Exposure resulted in a significant increase in intensity of reported anxiety and panic symptoms in anxious completers but not in nonanxious completers [Table 2; mean differences between anticipation and exposure: anxious completers: $\Delta=1.89$ and 1.03 for reported anxiety and intensity of symptoms, respectively; nonanxious completers: $\Delta=.06$ and .07 ; phase $\times$ group $\operatorname{Fs}(1,232)=75.42,66.60 ; \eta^{2}=.25$, .22 ; both ps $<.001]$.

Startle blink magnitudes significantly increased from the last minute of anticipation to the first minute of exposure [time $F(1,149)=41.87, p<.001, \eta^{2}=.22$; Figure 1] in both groups. Startle responses remained significantly potentiated during exposure for the anxious completers but not for the nonanxious completers [group $\mathrm{F}(1,149)=4.82, \mathrm{p}<.05, \eta^{2}=.03$ ], indicating that amygdala-dependent defensive reactivity was increased in anxious completers. 
Heart rate significantly increased from the last minute of anticipation to the first minute of exposure in anxious completers but not in the nonanxious completers [time $\times$ group $F(1,186)$ $\left.=7.99, \mathrm{p}<.01, \eta^{2}=.04\right]$. Again, HR remained elevated during the entire exposure period for anxious completers relative to nonanxious completers [group $\mathrm{F}(1,186)=14.39, \mathrm{p}<.001, \eta^{2}=$ .07].

Skin conductance level also significantly increased from the last minute of anticipation to first minute of exposure $\left[\right.$ time $\left.\mathrm{F}(1,199)=199.47, \mathrm{p}<.001, \eta^{2}=.50\right]$ in both groups. Again, SCL was larger in anxious completers compared with nonanxious completers [group $F(1,199)=$ $\left.12.13, \mathrm{p}<.001, \eta^{2}=.06\right]$.

Circa Strike: Escape Behavior. The increase in reported anxiety and panic symptoms during the exposure period ${ }^{3}$ was also stronger for escapers than for anxious completers [phase $\times$ group $\operatorname{Fs}(1,195)=18.89,19.02 ; \eta^{2}=.09, .09$; both $p s<.001$, for reported anxiety and panic symptoms, respectively; Table 2]. Increase in HR from the last minute of anticipation to the first minute of exposure was also significantly greater for escapers compared with anxious completers [time $\times$ group $\mathrm{F}(1,146)=6.84, \mathrm{p}<.01, \eta^{2}=.05$; Figure 1], supporting the selfreport data. ${ }^{4}$ In contrast, no significant differences between both groups were observed for startle potentiation [time $\times$ group $\mathrm{F}(1,107)=1, \eta^{2}=.01$ ]. There was, however, a significant inverse relationship between HR increase and startle potentiation in escapers, $r=-.39 ; p<$ $.05,{ }^{5}$ but not in anxious completers, $r=-.13, p=.32$, and nonanxious completers $r=-.02, p=$ .32. Following up on this finding, we analyzed the physiological responses 1 minute before the escape. Heart rate, as well as SCL, significantly increased during the last 60 seconds before escape [time $\operatorname{Fs}(5,125)=5.91,6.03 ; \eta^{2}=.19, .19$; both $\mathrm{ps}<.01$ for HR and SCL, respectively], ${ }^{6}$ indicating that the flight response was initiated at the peak of the autonomic surge. In contrast, blink magnitudes did not change during the last minute before escape [time $\mathrm{F}(2,50)=1, \eta^{2}=.03$ ] and were significantly smaller if compared with the startle responses elicited during the first minute of the exposure [time $\left.F(1,25)=4.78 ; p<.05, \eta^{2}=.16\right]$. Figure 2 illustrates HR and startle responses during the last 60 seconds before escape. Those patients who experienced a panic attack immediately before escape $(n=5)$ showed the strongest increase in autonomic arousal, while their startle responses significantly decreased [time, $\mathrm{F}(2,8)=4.81, \mathrm{p}<.05 ;$ Supplement 1].

Circa Strike: Panic Attacks. Twenty-six patients reported 34 panic attacks (range: 1-3) during exposure by pressing the panic button, enabling an event-related second by second analysis of physiology before and during the indicated panic attacks. ${ }^{7}$ Panic attacks were only

\footnotetext{
${ }^{3}$ For the escapers, ratings were obtained immediately after they left the dark chamber.

${ }^{4}$ From the group of 72 escapers, 17 patients left the dark room within the first minute, leaving only 55 patients who provided a complete dataset for the analysis of the physiological responses. Escapers who left the chamber within the first minute tended to show higher increases in $\operatorname{HR}(\Delta$ beats per minute $=16.55)$ than escapers who remained in the dark room for at least 1 minute $(\Delta$ beats per minute $=9.35)$, while there were no significant differences in the other variables, supporting the findings for the group comparisons including escapers with a complete dataset.

${ }^{5}$ When blink magnitudes were converted to T scores controlling for interindividual variability that was unrelated to the experimental condition, this inverse relationship between startle potentiation and HR increase was even more pronounced $(\mathrm{r}=-.56, \mathrm{p}<.01)$.

${ }^{6}$ Of the entire group of 72 escapers, only 26 patients could be included into these analyses because only these patients remained in the dark room for at least 120 seconds and provided reliable electrocardiogram, electrodermal activity, and electromyogram data during the last 60 seconds.

${ }^{7}$ Patients were only included if they received a current primary diagnosis of panic disorder and agoraphobia (as defined by the criteria of the DSM-IV [text revision]). All patients had to report recurrent panic attacks defined as discrete episodes of intense fear accompanied by at least four symptoms with the peak in severity within 10 minutes and concerns about the consequences of these attacks. Thus, all patients were familiar with the defining
} 
observed in escapers (16 attacks) and anxious completers (18 attacks; for comparison of these groups, see Supplement 1) but not in the nonanxious completers. Panic attacks were characterized by a significant increase in HR and SCL [time Fs $(18,180)=2.06,2.74 ; \eta^{2}=.17$, .22 ; both ps $<.01$ for HR and SCL, respectively; Figure $3 \mathrm{~A}] .{ }^{8}$ Interestingly, the significant increase in HR already started 20 seconds before the button press [from -30 to 0 sec: time $\left.\mathrm{F}(6,60)=2.48, \mathrm{p}<.05, \eta^{2}=.21\right]$, suggesting that the perceived increase in HR might have triggered the button press. Again, blink magnitudes showed an opposite response pattern. Figure 3B depicts the HR changes and blink responses of those 11 panic attacks for whom data from both variables were complete.

\section{Recovery Period}

Results are reported in Supplement 1.

\section{Discussion}

The current study investigated defensive reactivity during exposure to a small, dark chamber in a large group of PD/AG patients. The selection of this highly standardized BAT was guided by the hypothesis that fears of restriction and suffocation are not only hallmark symptoms in claustrophobic patients (10) but are also prominent symptoms in patients with PD/AG (12). In fact, this BAT clearly elicited strong defensive reactivity as indexed by self-reported distress, physiological arousal, ${ }^{9}$ and fear-potentiated startle in over two thirds of the patients. Since this behavioral task did not require any motor acts that would affect physiological responses substantially (like in the early behavioral walk paradigms [24,25]), it proved to be a highly useful tool to assess the dynamics of defensive reactivity in the majority of $\mathrm{PD} / \mathrm{AG}$ patients. We found evidence that defensive reactivity of these patients was organized in a comparable way as described for animals in the predator-imminence model (26). With increasing intensity of bodily symptoms, i.e., increasing imminence of interoceptive threat, defensive reactivity switches from anxious apprehension to circa strike defense.

\section{Defensive Reactivity During Anxious Apprehension}

Patients who reported elevated anxiety and more symptoms during the BAT and completed the task showed a significant increase in HR and SCL, indicating augmented sympathetic arousal that was maintained during the entire exposure period indicating sustained anxious apprehension in this patient group. Accordingly, startle response magnitudes were also potentiated. While darkness seems to be a potentially threatening context also for nonanxious individuals (replicating previous findings [4,27], startle responses were also facilitated during

\footnotetext{
characteristics of a panic attack. Furthermore, all patients reporting a panic attack during the BAT reported intense fear (mean score: 9.04, SD =.92) and between 6 and 13 somatic and cognitive symptoms (mean score: 9.77, $\mathrm{SD}=2.25$ ) with moderate mean intensity (mean score: $5.65, \mathrm{SD}=1.70$ ) after they left the chamber. ${ }^{8}$ Of a total of 34 panic attacks, only 11 panic attacks could be analyzed with available electrocardiogram, electrodermal activity, and electromyogram data that were recorded 30 seconds before and 60 seconds after panic onset.

${ }^{9}$ Increase in autonomic arousal (e.g., heart rate) in the current BAT was, on average, 10 beats per minute for escapers and about 15 beats per minute during an acute panic attack in both escapers and anxious completers, suggesting that this task is indeed very robust to produce strong defensive response mobilization at least in some of the patients. These Increases in autonomic arousal are even more striking when compared with other challenges that have been used with these patients, like threat of shock, emotional imagery, or slide viewing, where heart rate only increases by two to three beats per minute or even decreases, as in the case of slide viewing.
} 
exposure to darkness in nonanxious patients), startle potentiation was significantly stronger for those patients who also showed elevated sympathetic arousal and reported more anxiety. Similar to increased physiological arousal, fear-potentiated startle did not habituate but was rather maintained over the entire exposure period, similar to the sustained potentiation of the startle reflex that can be observed in animals during an unsafe context in which painful stimuli could occur (2).

\section{Defensive Reactivity During Active Escape}

Startle modulation changed substantially when defensive behavior changed from anxious apprehension into an active flight response. Seventy-two patients actively escaped from the chamber. While 17 patients fled from the chamber within the first minute, 55 patients stayed long enough to obtain reliable measures of defensive reactivity 1 minute before the flight response. Autonomic arousal increased linearly 1 minute before active escape behavior initiated at the peak of the autonomic surge, supporting the hypothesis that this strong increase in somatic symptoms was an imminent threat for these patients. In contrast, startle responses were inversely correlated with HR increases during early exposure and were relatively inhibited during the autonomic surge before escape when compared with the anxious apprehension at the beginning of the exposure period. These data are in line with the results by Löw et al. (17) who showed that increases in HR and SCL were accompanied by a relative inhibition of the startle reflex immediately before fear-related action responses in healthy volunteers. These data are also in line with the predator-imminence model $(26,28,29)$. When a remote threat is encountered (anxious apprehension), the organism becomes hypervigilant and ventrolateral columns of the periaqueductal gray (PAG) evoke behavioral adjustments like freezing to support the attentive scanning of the potentially dangerous context. Under these circumstances, defensive reflexes like the startle responses are potentiated (30). When the threat becomes more imminent, the dorsolateral PAG becomes dominant, controlling active defensive behavior like flight or fight. Using an artificial intelligence predator model to study the dynamics of defensive reactivity in humans, Mobbs et al. $(31,32)$ found that postencounter defense preferentially activated the ventromedial prefrontal cortex, subgenual anterior cingulate cortex, amygdala, hippocampus, and hypothalamus, while circa strike engaged the PAG and the dorsal anterior cingulate cortex, which is also involved in analgesia (33). The inhibition of the startle response observed immediately before escape is in accordance with these results, suggesting that - parallel to analgesia — protective reflexes are also inhibited during active escape. A possible mechanism for this inhibition is that processing of external cues might be reduced during circa strike to facilitate escape. Recent findings observing more errors in a secondary task during panic attacks (32) would also support this interpretation and would suggest that acute panic attacks can be conceptualized as circa-strike defense.

Defensive Reactivity During Acute Panic Attacks In the current study, we recorded 34 panic attacks in real time during the exposure to the dark room. Paralleling the response pattern immediately before escape, panic attacks were also characterized by strong increases in HR and SCL. Again, in contrast to the increase in autonomic arousal, startle blink magnitudes were relatively inhibited during the acute panic attack compared with the startle responses elicited before the panic attacks. These data support a learning theory perspective of the etiology of PD, suggesting that acute panic attacks and anxious apprehension are distinct emotional phenomena $(1,8)$. The defensive response pattern observed during an acute panic attack resembles the pattern of activity that was observed immediately before escape, suggesting that the panic attack could be considered as a typical circa-strike defense probably linked to the activation of the dorsal PAG. Animal data show that chemical stimulation of the 
dorsolateral PAG in rodents elicits panic-like behavior (like vigorous running [34]). Indeed, several patients escaped from the chamber at the peak of their panic attack.

In line with findings from an ambulatory monitoring study of spontaneous panic attacks (35), increase in HR but also SCL started before patients pressed the panic button, suggesting that the increase in autonomic arousal indeed triggered the subjective experience of the panic attack. These data are also in line with the learning perspective of PD, stating that weak and early physical panic symptoms are associated with full-blown panic attacks and thus can serve as conditioned stimuli triggering future panic attacks. Besides these interoceptive cues, exteroceptive stimuli might have also contributed to the onset of the panic attacks, particularly because only patients with PD/AG were included in the study. The autonomic surge decreased already after 1 minute, thus supporting earlier observations $(36,37)$ monitoring panic attacks in individual cases and finding that even strong panic attacks subside within about 5 minutes.

\section{Limitations}

Despite the overall large sample size, analyses of specific physiological response patterns during circa-strike defense had to be restricted to those patients for whom a complete dataset across all physiological measures was available. This resulted in a quite substantial loss of data. Therefore, the current findings need to be replicated in future research with larger sample sizes. Moreover, while we had continuous measures of physiological reactivity, we did not continuously record verbal report of anxious apprehension. Therefore, we cannot rule out that the reported feeling of anxious apprehension might have increased before or in parallel to the increase in the autonomic measures. Future research should continuously assess these verbal report data to further clarify the associations between the different response systems during the defense cascade.

\section{Summary}

Although all patients of the current sample received the principal diagnosis of $\mathrm{PD} / \mathrm{AG}$, defensive reactivity in the standardized BAT differed quite substantially between these patients. Defensive reactions ranged from anxious apprehension to circa-strike defense. Moreover, 39 patients refused to enter the dark chamber. These avoiders were clinically more severely impaired and scored higher on the Beck Depression Inventory than the nonanxious completers but did not differ significantly in these variables from the escapers. However, $58.9 \%$ of the avoiders had three or more comorbid diagnoses compared with $42.5 \%$ of the escapers, suggesting that these patients exhibit more severe psychopathology. These data confirm recent evidence from McTeague et al. (38) who found clear differences in defensive reactivity between $\mathrm{PD} / \mathrm{AG}$ patients depending upon general symptom severity. Whether different genetic dispositions also contribute to these differences in defensive reactivity is an open question that needs to be evaluated in future research. Moreover, future research has to elucidate whether differences in defensive reactivity of $\mathrm{PD} / \mathrm{AG}$ patients could be used to predict treatment outcome. 
A

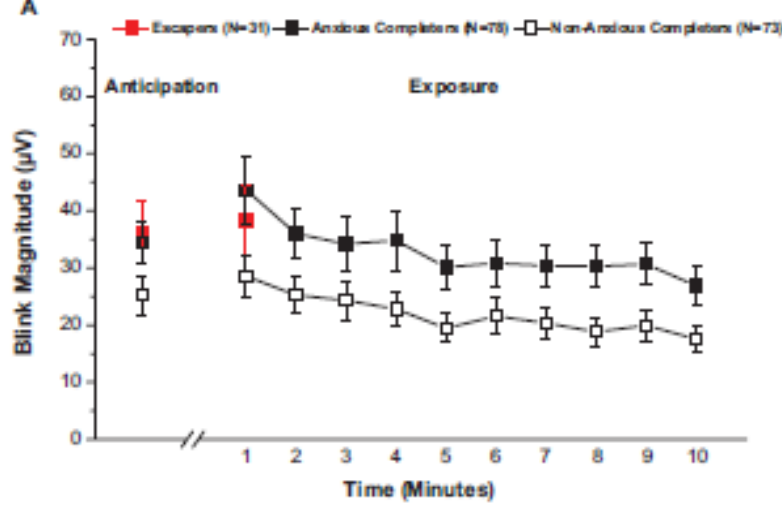

B

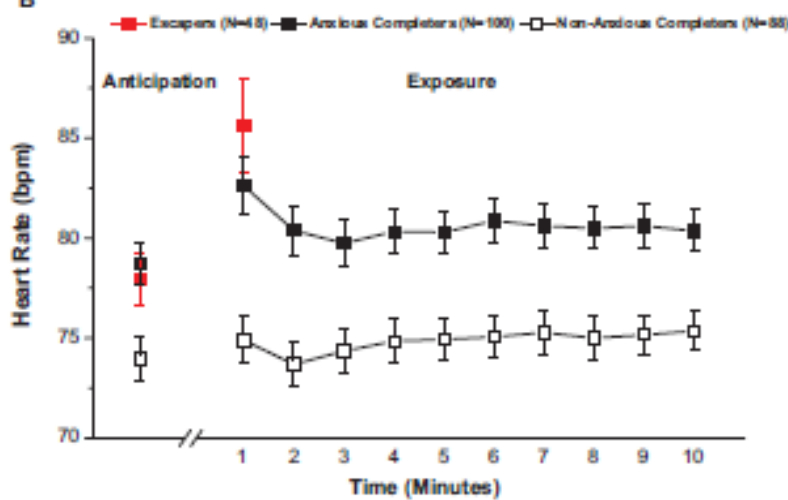

c

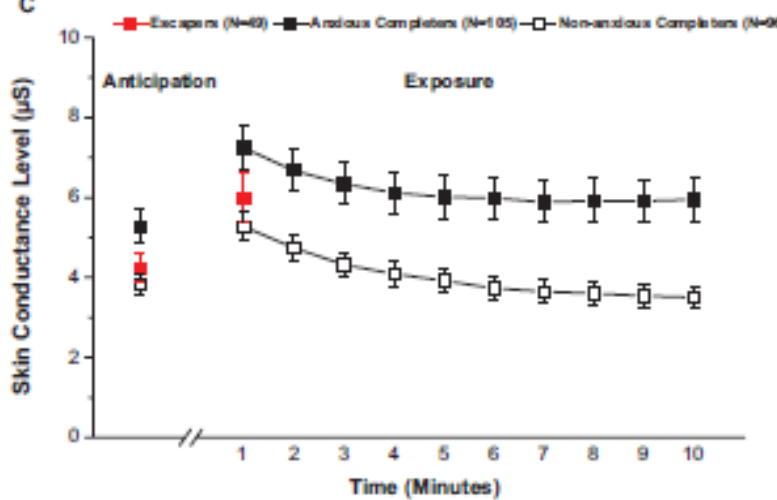

Figure 1. Physiological responses (startle blink magnitudes [A], heart rate [B], and skin conductance level [C] during anticipation (mean block score) and during the 10 minutes of the exposure period in anxious completers and nonanxious completers. For the escapers, physiological responses are depicted for the first minute of the exposure period. bpm, beats per minute. 


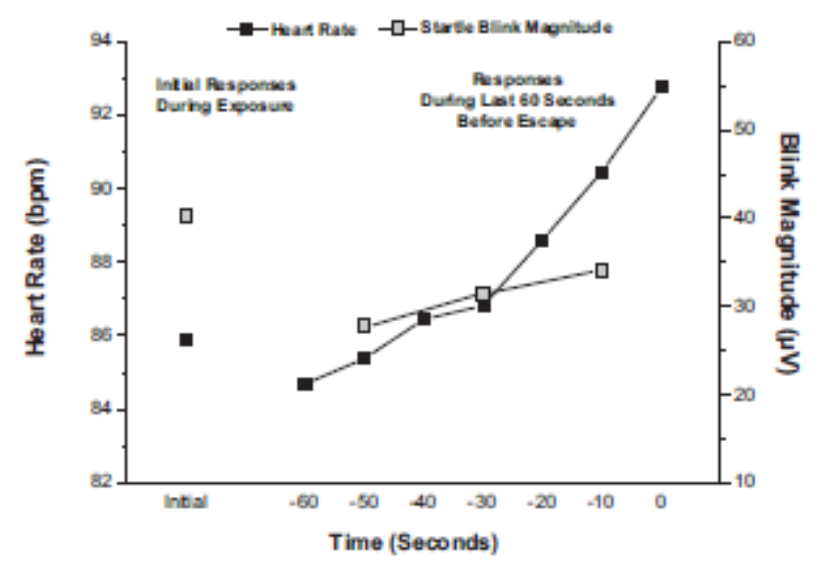

Figure 2. Mean heart rate and startle response magnitudes during the initial 60 seconds of the exposure period and the 60 seconds before the escape (startle responses to three probes) from the dark room. bpm, beats per minute.

A
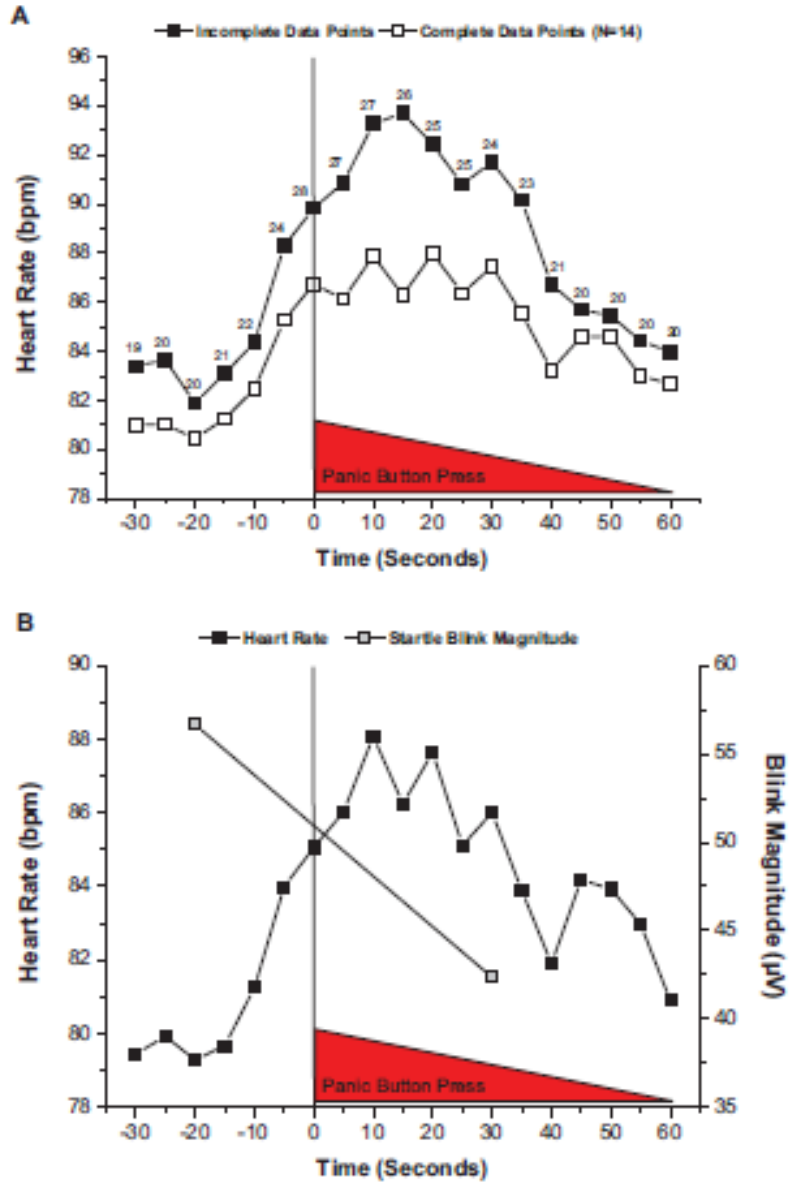

Figure 3. (A) Heart rate changes before ( 30 seconds), during, and after (60 seconds) the button press of the reported panic attacks. The numbers above the filled squares refer to the number of patients who contributed to each data point. The open squares show the heart rate data of those patients for whom a complete dataset throughout the entire sampling period was available. (B) Heart rate changes and blink magnitudes (mean magnitudes of last two responses before button press versus first three responses after button press) of those 11 panic attacks for which both datasets were available before and during the reported panic attacks. bpm, beats per minute. 
Table 1. Gender Distribution, Age, and Severity of Panic/Agoraphobic and Depressive Symptoms for the Four Groups

\begin{tabular}{|c|c|c|c|c|c|}
\hline & $\begin{array}{l}\text { Avoiders } \\
(n=39)\end{array}$ & $\begin{array}{l}\text { Escapers } \\
(n=72)\end{array}$ & $\begin{array}{l}\text { Anxious } \\
\text { Completers } \\
(n=125)\end{array}$ & $\begin{array}{l}\text { Nonanxious } \\
\text { Completers } \\
(n=109)\end{array}$ & \\
\hline \multicolumn{6}{|c|}{$n(\%)$} \\
\hline Gender & & & & & \\
\hline Male & $5(12.8)$ & $7(9.7)$ & $32(25.6)$ & $42(38.5)$ & $x^{2}(3)=22.76$ \\
\hline Female & $34(87.2)$ & 65 (90.3) & 93 (74.4) & $67(61.5)$ & $p<.001$ \\
\hline \multicolumn{6}{|c|}{ Mean (SD) } \\
\hline Age (Years) & $36.36(10.16)$ & $34.21(10.61)$ & $33.88(10.94)$ & $37.16(10.52)$ & $\begin{array}{c}F(3,341)=2.22 \\
p=.09\end{array}$ \\
\hline SIGH-A (0-56) & $25.31(8.56)^{a}$ & $25.25(7.45)^{a}$ & $24.01(6.86)^{a b}$ & $21.86(6.32)^{b}$ & $\begin{array}{c}F(3,341)=4.39 \\
p<.01\end{array}$ \\
\hline CGI (1-7) & $5.44(.79)^{a}$ & $5.25(.58)^{a b}$ & $5.17(80)^{a b}$ & $4.99(.81)^{b}$ & $\begin{array}{c}F(3,341)=3.84 \\
p<.01\end{array}$ \\
\hline Number of Panic Attacks (0-3) & $2.62(2.53)^{a b}$ & $2.83(2.43)^{a b}$ & $2.87(2.46)^{a}$ & $2.05(2.09)^{b}$ & $\begin{array}{c}F(3,341)=2.79 \\
p<.05\end{array}$ \\
\hline $\operatorname{PAS}(0-57)$ & $29.42(10.41)^{a}$ & $29.29(8.77)^{a}$ & $29.33(9.71)^{a}$ & $24.71(9.56)^{b}$ & $\begin{array}{c}F(3,341)=5.83 \\
p<.001\end{array}$ \\
\hline$A C Q(1-5)$ & $2.35(.59)^{a}$ & $2.18(.59)^{a b}$ & $2.24(.59)^{a b}$ & $2.07(50)^{6}$ & $\begin{array}{c}F(3,341)=3.13 \\
p<.05\end{array}$ \\
\hline BSQ (17-85) & $52.90(12.86)^{a}$ & $49.17(13.01)^{a b}$ & $48.87(12.49)^{a b}$ & $45.73(11.04)^{b}$ & $\begin{array}{c}F(3,341)=3.66 \\
p<.05\end{array}$ \\
\hline MI Alone (1-5) & $3.18(.87)^{a}$ & $3.16(.85)^{a}$ & $3.03(.75)^{a}$ & $2.68(.82)^{6}$ & $\begin{array}{c}F(3,311)=6.55 \\
p<.001\end{array}$ \\
\hline $\mathrm{BDI}-11(0-63)$ & $18.19(9.78)^{a b}$ & $16.96(9.46)^{a b}$ & $18.09(7.91)^{a}$ & $14.89(8.73)^{b}$ & $\begin{array}{c}F(3,341)=2.98 \\
p<.05\end{array}$ \\
\hline$C L Q(0-96)$ & $66.91(19.02)^{a}$ & $64.93(19.57)^{\sigma}$ & $56.24(18.23)^{b}$ & $45.70(21.73)^{\mathrm{F}}$ & $\begin{array}{c}F(3,341)=18.74 \\
p<.001\end{array}$ \\
\hline \multicolumn{6}{|l|}{$\begin{array}{l}\text { Comorbid Diagnosis of } \\
\text { Specific Phobia } \\
\text { (Situational Type) }\end{array}$} \\
\hline Yes & $26(66.7)$ & $45(62.5)$ & $66(52.8)$ & $63(57.8)$ & $x^{2}(3)=11.74$ \\
\hline No & $13(33.3)$ & $27(37.5)$ & $59(47.2)$ & $46(42.2)$ & $p<.01$ \\
\hline
\end{tabular}

Table 2. Means and Standard Deviations of Verbal Reports and Physiological Responses for the Four Groups During Anticipation and Exposure Period

\begin{tabular}{|c|c|c|c|c|c|}
\hline & Avoiders & Escapers & $\begin{array}{l}\text { Anxious } \\
\text { Completers }\end{array}$ & $\begin{array}{l}\text { Nonanxious } \\
\text { Completers }\end{array}$ & \\
\hline \multicolumn{6}{|c|}{ Anticipation Period } \\
\hline Reported Anxiety (1-10) & $\begin{array}{c}4.36(2.56)^{a} \\
(n=29)\end{array}$ & $\begin{array}{c}4.25(2.13)^{a} \\
(n=72)\end{array}$ & $\begin{array}{c}3.89(1.90)^{a} \\
(n=125)\end{array}$ & $\begin{array}{c}2.11(1.19)^{b} \\
(n=109)\end{array}$ & $\begin{array}{c}F(3,331)=28.92 \\
p<.001\end{array}$ \\
\hline Intensity of Panic Symptoms (1-10) & $\begin{array}{l}2.77(2.03)^{a} \\
(n=29)\end{array}$ & $\begin{array}{c}2.49(1.37)^{a} \\
(n=72)\end{array}$ & $\begin{array}{c}2.37(1.21)^{a} \\
(n=125)\end{array}$ & $\begin{array}{c}1.44(0.49)^{b} \\
(n=109)\end{array}$ & $\begin{array}{c}F(3,331)=19.52 \\
p<.001\end{array}$ \\
\hline Startle Response Magnitude $(\mu \mathrm{V})$ & $\begin{array}{c}21.25(15.69) \\
(n=15)\end{array}$ & $\begin{array}{c}36.22(37.23) \\
(n=44)\end{array}$ & $\begin{array}{c}34.33(31.87) \\
(n=78)\end{array}$ & $\begin{array}{c}25.17(29.06) \\
(n=75)\end{array}$ & $\begin{array}{c}F(3,208)=2.04 \\
p=.11\end{array}$ \\
\hline Heart Rate (bpm) & $\begin{array}{c}82.64(17.69)^{a} \\
(n=25)\end{array}$ & $\begin{array}{c}77.90(10.35)^{a} \\
(n=64)\end{array}$ & $\begin{array}{c}78.73(10.52)^{a b} \\
(n=102)\end{array}$ & $\begin{array}{c}73.95(10.04)^{b} \\
(n=88)\end{array}$ & $\begin{array}{c}F(3,275)=5.19 \\
p<.01\end{array}$ \\
\hline Skin Conductance Level ( $\mu \mathrm{S})$ & $\begin{array}{c}5.52(3.93)^{a b} \\
(n=22)\end{array}$ & $\begin{array}{c}4.24(3.02)^{d b} \\
(n=65)\end{array}$ & $\begin{array}{r}5.27(4.43)^{a} \\
(n=106)\end{array}$ & $\begin{array}{c}3.83(2.73)^{b} \\
(n=97)\end{array}$ & $\begin{array}{c}F(3,286)=3.42 \\
p<.05\end{array}$ \\
\hline \multicolumn{6}{|c|}{ Exposure Period } \\
\hline Reported Anxiety (1-10) & & $\begin{array}{c}7.42(2.12)^{a} \\
(n=72)\end{array}$ & $\begin{array}{c}5.78(1.76)^{b} \\
(n=125)\end{array}$ & $\begin{array}{c}2.17(0.80)^{c} \\
(n=109)\end{array}$ & $\begin{array}{c}F(2,303)=268.49 \\
p<.001\end{array}$ \\
\hline Intensity of Panic Symptoms (1-10) & & $\begin{array}{c}4.29(1.89)^{a} \\
(n=72)\end{array}$ & $\begin{array}{c}3.40(1.45)^{b} \\
(n=125)\end{array}$ & $\begin{array}{c}1.51(0.50)^{5} \\
(n=109)\end{array}$ & $\begin{array}{c}F(2,303)=106.81 \\
p<.001\end{array}$ \\
\hline Startle Response Magnitude $(\mu \mathrm{V})$ & & $\begin{array}{c}39.76(46.28)^{a} \\
(n=38)\end{array}$ & $\begin{array}{c}32.79(35.54)^{a b} \\
(n=78)\end{array}$ & $\begin{array}{c}21.87(24.13)^{b} \\
(n=73)\end{array}$ & $\begin{array}{c}F(2,186)=3.85 \\
p<.05\end{array}$ \\
\hline Heart Rate (bpm) & & $\begin{array}{c}87.48(15.39)^{a} \\
(n=63)\end{array}$ & $\begin{array}{c}80.63(10.91)^{b} \\
(n=100)\end{array}$ & $\begin{array}{c}74.86(9.81)^{5} \\
(n=88)\end{array}$ & $\begin{array}{c}F(2,248)=20.87 \\
p<.001\end{array}$ \\
\hline Skin Conductance Level ( $\mu \mathrm{S}$ ) & & $\begin{array}{c}5.83(3.99)^{a} \\
(n=64)\end{array}$ & $\begin{array}{c}6.20(5.45)^{a} \\
(n=105)\end{array}$ & $\begin{array}{c}4.04(2.84)^{b} \\
(n=96)\end{array}$ & $\begin{array}{c}F(2,262)=6.90 \\
p=.001\end{array}$ \\
\hline \multicolumn{6}{|c|}{ Recovery Period } \\
\hline Reported Anxiety (1-10) & $\begin{array}{c}3.17(2.19)^{a} \\
(n=21)\end{array}$ & $\begin{array}{c}2.69(1.89)^{a} \\
(n=72)\end{array}$ & $\begin{array}{c}2.62(1.55)^{a} \\
(n=125)\end{array}$ & $\begin{array}{c}1.35(0.66)^{b} \\
(n=109)\end{array}$ & $\begin{array}{c}F(3,323)=21.39 \\
p<.001\end{array}$ \\
\hline Intensity of Panic Symptoms (1-10) & $\begin{array}{c}1.87(1.01)^{a} \\
(n=21)\end{array}$ & $\begin{array}{c}2.02(1.24)^{a} \\
(n=72)\end{array}$ & $\begin{array}{c}1.91(0.88)^{a} \\
(n=125)\end{array}$ & $\begin{array}{c}1.21(0.29)^{b} \\
(n=109)\end{array}$ & $\begin{array}{c}F(3,323)=18.16 \\
p<.001\end{array}$ \\
\hline Startle Response Magnitude $(\mu \mathrm{V})$ & $\begin{array}{c}28.36(19.79) \\
(n=8)\end{array}$ & $\begin{array}{c}27.08(31.16) \\
(n=44)\end{array}$ & $\begin{array}{c}27.72(30.99) \\
(n=77)\end{array}$ & $\begin{array}{c}16.75(18.28) \\
(n=71)\end{array}$ & $\begin{array}{c}F(3,196)=2.48 \\
p=.06\end{array}$ \\
\hline Heart Rate (bpm) & $\begin{array}{c}77.59(15.63) \\
(n=15)\end{array}$ & $\begin{array}{c}74.83(9.18) \\
(n=60)\end{array}$ & $\begin{array}{c}77.14(8.94) \\
(n=103)\end{array}$ & $\begin{array}{c}73.56(8.94) \\
(n=85)\end{array}$ & $\begin{array}{c}F(3,259)=2.56 \\
p=.06\end{array}$ \\
\hline Skin Conductance Level ( $\mu \mathrm{S}$ ) & $\begin{array}{c}4.99(3.76)^{a b} \\
(n=16)\end{array}$ & $\begin{array}{c}4.29(3.17)^{d t} \\
(n=61)\end{array}$ & $\begin{array}{c}6.01(5.32)^{a} \\
(n=110)\end{array}$ & $\begin{array}{l}4.29(3.25)^{b} \\
(n=98)\end{array}$ & $\begin{array}{c}F(3,281)=3.65 \\
p<.05\end{array}$ \\
\hline
\end{tabular}

Varying superscripts indicate significant mean differences tested with Bonferroni corrected post hoc comparisons with $p<.05$.

bpm, beats per minute.

$a, b, c$ Means with the same superscripts (e.g, $a, b$, or $c$ ) indicate that these groups did not differ significantly. Different superscripts (e.g., $a$ for group 1, $b$ for group 2, and c for group 3) indicate significant differences between the corresponding groups tested with Bonferroni corrected post hoc comparisons with $p<.05$.

Means were not significantly different from the means with superscripts $a$ and $b$. 
This work is part of the German multicenter trial "Mechanisms of Action in CBT" (MAC). The MAC study is funded by the German Federal Ministry of Education and Research (project number 01GV0615) as part of the German Federal Ministry of Education and Research Psychotherapy Research Funding Initiative.

Centers: Principal investigators (PI) with respective areas of responsibility in the MAC study are V. Arolt (Münster: Overall MAC Program Coordination), H.U. Wittchen (Dresden: PI for the Randomized Clinical Trial and Manual Development), A. Hamm (Greifswald: PI for Psychophysiology), A.L. Gerlach (Münster: PI for Psychophysiology and Panic subtypes), A. Ströhle (Berlin: PI for Experimental Pharmacology), T. Kircher (Marburg: PI for functional neuroimaging), and J. Deckert (Würzburg: PI for Genetics). Additional site directors in the Randomized Clinical Trial component of the program are G.W. Alpers (Würzburg), T. Fydrich and L. Fehm (Berlin-Adlershof), and T. Lang (Bremen).

Data access and responsibility: All principal investigators take responsibility for the integrity of the respective study data and their components. All authors and co-authors had full access to all study data. Data analysis and manuscript preparation were completed by the authors and co-authors of this article, who take responsibility for its accuracy and content.

Acknowledgements and staff members by site: Greifswald (coordinating site for psychophysiology): Christiane Pané-Farré, Jan Richter, Susan Richter, and Matthias von Rad; Berlin-Charité (coordinating center for experimental pharmacology): Harald Bruhn, Anja Siegmund, Meline Stoy, and Andre Wittmann; Berlin-Adlershof: Irene Schulz; Münster (Overall MAC Program Coordination, Genetics and Functional Neuroimaging): Andreas Behnken, Katharina Domschke, Adrianna Ewert, Carsten Konrad, Bettina Pfleiderer, and Peter Zwanzger; Münster (coordinating site for psychophysiology and subtyping): Judith Eidecker, Swantje Koller, Fred Rist, and Anna Vossbeck-Elsebusch; Marburg/ Aachen (coordinating center for functional neuroimaging): Barbara Drüke, Sonja Eskens, Thomas Forkmann, Siegfried Gauggel, Susan Gruber, Andreas Jansen, Thilo Kellermann, Isabelle Reinhardt, and Nina Vercamer-Fabri; Dresden (coordinating site for data collection, analysis, and the Randomized Clinical Trial ): Franziska Einsle, Christine Fröhlich, Andrew T. Gloster, Christina Hauke, Simone Heinze, Michael Höfler, Ulrike Lueken, Peter Neudeck, Stephanie Preiß, and Dorte Westphal; Würzburg Psychiatry Department (coordinating center for genetics): Andreas Reif; Würzburg Psychology Department: Julia Dürner, Hedwig Eisenbarth, Antje B. M. Gerdes, Harald Krebs, Paul Pauli, Silvia Schad, and Nina Steinhäuser; Bremen: Veronika Bamann, Sylvia Helbig-Lang, Anne Kordt, Pia Ley, Franz Petermann, and Eva-Maria Schröder. Additional support was provided by the Coordinating Center for Clinical Studies in Dresden (CCS Dresden): Xina Grählert and Marko Käppler.

The Randomized Clinical Trial project was approved by the Ethics Committee of the Medical Faculty of the Technical University of Dresden (EK 164082006). The neuroimaging components were approved by the Ethics Committee of the Medical Faculty of the RheinischWestfälische Hochschule University Aachen (EK 073/07). The experimental pharmacology study was approved by the Ethics Committee of the state of Berlin (EudraCT: 2006-00-486029).

J. Deckert received speaker honoraria by Janssen, Bristol Myers-Squibb, Wyeth, Lundbeck, Astra-Zeneca, and Pfizer and grant support by Medice, Novartis, and Alkermes.

A. Ströhle received research funding from the German Federal Ministry of Education and Research, the European Commission (FP6), and Lundbeck and speaker honoraria from 
Pfizer, Eli Lilly \& Co, Wyeth, Lundbeck, AstraZeneca, Boehringer Ingelheim, Bristol-Myers Squibb, and UCB. A. Ströhle was the recipient of educational grants by the Stifterverbandfür die Deutsche Wissenschaft, the Berlin Brandenburgische Akademie der Wissenschaften, the Boehringer Ingelheim Fonds, and the Eli Lilly International Foundation.

T. Kircher received fees for educational programs from Janssen-Cilag, Eli Lilly, Servier, Lundbeck, Bristol Myers-Squibb, Pfizer, and Astra-Zeneca; travel support/sponsorship for congresses from Servier; speaker's honoraria from Janssen-Cilag; and research grants from Pfizer and Lundbeck.

$V$. Arolt is member of advisory boards and/or gave presentations for the following companies: Astra-Zeneca, Janssen-Organon, Eli Lilly, Lundbeck, Pfizer, Servier, and Wyeth. He also received grants from Astra-Zeneca, Lundbeck, and Wyeth. He chaired the committee for the "Wyeth Research Award Depression and Anxiety." These cooperations have no relevance to the work covered in the manuscript.

All other authors reported no biomedical financial interests or potential conflicts of interest.

ISRCTN: Improving cognitive behavioural therapy for panic by identifying the active ingredients and understanding the mechanisms of action: a multicentre study; http://www.controlled-trials.com/isrctn/pf/80046034; 040203-17.

Supplementary material cited in this article is available online.

1. Bouton ME, Mineka S, Barlow DH (2001): A modern learning theory perspective on the etiology of panic disorder. Psychol Rev 18:4 -32 .

2. Davis M, Walker DL, Miles L, Grillon C (2010): Phasic vs sustained fear in rats and humans: Role of the extended amygdala in fear vs anxiety. Neuropsychopharmacology 35:105-135.

3. Grillon C, Ameli R, Goddard A, Woods SW, Davis M (1994): Baseline and fearpotentiated startle in panic disorder patients. Biol Psychiatry 35: 431-439.

4. Melzig CA, Weike AI, Zimmermann J, Hamm AO (2007): Startle reflex modulation and autonomic responding during anxious apprehension in panic disorder patients.

Psychophysiology 44:846-854.

5. Grillon C, Lissek S, Rabin S, McDowell D, Dvir S, Pine DS (2008): Increased anxiety during anticipation of unpredictable but not predictable aversive stimuli as a psychophysiologic marker of panic disorder. Am J Psychiatry 165:898 -904.

6. Fanselow MS (1994): Neural organization of the defensive behavior system responsible for fear. Psychon Bull Rev 1:429-438.

7. Lang PJ, Bradley MM, Cuthbert BN (1997): Motivated attention: Affect, activation, and action. In: Lang PJ, Simons RF, Balaban MT, editors. Attention and Orienting: Sensory and Motivational Processes. Mahwah, NJ: Lawrence Erlbaum Associates Publishers, 97-135. 8. Mineka S, Zinbarg R (2006): A contemporary learning theory perspective on the etiology of anxiety disorders: It's not what you thought it was. Am Psychol 61:10 -26.

9. Melzig CA, Holtz K, Michalowski JM, Hamm AO (2011): Interoceptive threat leads to defensive mobilization in highly anxiety sensitive persons. Psychophysiology 48:745-754. 10. Rachman S, Taylor S (1993): Analyses of claustrophobia. J Anxiety Disord 7:281-291. 
11. Curtis GC, Hill EM, Lewis JA (1990): Heterogeneity of DSM-III-R simple phobia and the simple phobia/agoraphobia boundary: Evidence from the ECA study. Report to the DSM-IV Anxiety Disorders Workgroup. Ann Arbor, MI: University of Michigan.

12. Curtis GC, Himle JA, Lewis JA, Lee Y (1989): Specific situational phobias: Variant of agoraphobia? Report to the DSM-IV Anxiety Disorders Workgroup. Ann Arbor, MI: University of Michigan.

13. McNally RJ (1990): Psychological approaches to panic disorder: A review. Psychol Bull 108:403- 419.

14. Craske M, Zarate R, Burton T, Barlow DH (1993): Specific fears and panic attacks: A survey of clinical and nonclinical samples. J Anxiety Disord 7:1-19.

15. Öst LG, Johansson J, Jerremalm A (1982): Individual response patterns and the effects of different behavioral methods in the treatment of claustrophobia. Behav Res Ther 20:445-460. 16. Lang PJ, Davis M, Ohman A (2000): Fear and anxiety: Animal models and human cognitive psychophysiology. J Affect Disord 61:137-159.

17. Löw A, Lang PJ, Smith JC, Bradley MM (2008): Emotional arousal in threat and reward. Psychol Sci 19:865- 873.

18. Gloster AT, Wittchen HU, Einsle F, Höfler M, Lang T, Helbig-Lang S, et al. (2009): Mechanism of action in CBT (MAC): Methods of a multi-center randomized controlled trial in 369 patients with panic disorder and agoraphobia. Eur Arch Psychiatry Clin Neurosci 259(suppl 2):S155-S166.

19. Gloster AT, Wittchen H-U, Einsle F, Lang T, Helbig-Lang S, Fydrich T, et al. (2011): Psychological treatment for panic disorder with agoraphobia: A randomized controlled trial to examine the role of therapist-guided exposure in situ in CBT. J Consult Clin Psychol 79:406420.

20. Wittchen HU, Pflister H (1997): DIA-X Interview. [Instruction Manual for the DIA-XInterview]. Frankfurt, Germany: Swets \& Zeitlinger.

21. Cook III E, Atkinson L, Lang K (1987): Stimulus control and data acquisition for IBM PCs and compatibles. Psychophysiology 24:726-727.

22. Wilhelm F, Peyk P (2005): ANSLAB: Autonomic Nervous System Laboratory (Version 4.0). Available at the Society for Psychophysiological Research Software Repository: http://www.sprweb.org. Accessed at April 10, 2006.

23. Limberg A, Barnow S, Freyberger HJ, Hamm AO (2011): Emotional vulnerability in borderline personality disorder is cue specific and modulated by traumatization. Biol Psychiatry 69:574 -582.

24. Vermilyea JA, Boice R, Barlow DH (1984): Rachman and Hodgson (1974) a decade later: How do desynchronous response systems relate to the treatment of agoraphobia? Behav Res Ther 22:615-621.

25. Michelson L (1990): Psychophysiological outcome of cognitive, behavioral and psychophysiologically-based treatments of agoraphobia. Behav Res Ther 28:127-139. 26. Blanchard R, Blanchard D (1990): Anti-predator defense as models of animal fear and anxiety. In: Brain P, Parmigiani S, Blanchard R, Mainardi D, editors. Fear and Defense. Amsterdam: Harwood Academic Publishers, 89-108.

27. Grillon C, Pellowski M, Merikangas KR, Davis M (1997): Darkness facilitates the acoustic startle reflex in humans. Biol Psychiatry 42:453-460. 28. Craske M (1999): Anxiety Disorders: Psychological Approaches to Theory and Treatment. Boulder, CO: Westview Press.

29. Rau V, Fanselow M (2007): Neurobiological and neuroethological perspectives on fear and anxiety. In: Kirmayer LJ, Lemesom R, Barad M, editors. Understanding Trauma: Integrating Biological, Clinical, and Cultural Perspectives. New York: Cambridge University Press, 27-40. 30. Lang PJ, Davis M (2006): Emotion, motivation, and the brain: Reflex foundations in animal and human research. Prog Brain Res 15:63-29. 
31. Mobbs D, Petrovic P, Marchant JL, Hassabis D, Weiskopf N, Seymour B, et al. (2007): When fear is near: Threat imminence elicits prefrontal-periaqueductal gray shifts in humans. Science 317:1079-1083.

32. Mobbs D, Marchant JL, Hassabis D, Seymour B, Tan G, Gray M, et al. (2009): From threat to fear: The neural organization of defensive fear systems in humans. J Neurosci 29:12236-12243.

33. Petrovic P, Kalso E, Petersson KM, Ingvar M (2002): Placebo and opioid analgesia-imaging a shared neuronal network. Science 295:1737-1740.

34. Bandler R, Keay KA, Floyd N, Price J (2000): Central circuits mediating patterned autonomic activity during active vs. passive emotional coping. Brain Res Bull 53:95-104. 35. Meuret AE, Rosenfield D, Wilhelm FH, Zhou E, Conrad A, Ritz T, Roth WT (2011): Do unexpected panic attacks occur spontaneously? Biol Psychiatry 70:985-991.

36. Freedman RR, Ianni P, Ettedgui E, Puthezhath N (1985): Ambulatory monitoring of panic disorder. Arch Gen Psychiatry 42:244 -248.

37. Cohen AS, Barlow DH, Blanchard EB (1985): Psychophysiology of relaxation- associated panic attacks. J Abnorm Psychol 94:96 -101.

38. McTeague LM, Lang PJ, Laplante M-C, Bradley MM (2011): Aversive imagery in panic disorder: Agoraphobia severity, comorbidity, and defensive physiology. Biol Psychiatry $70: 415-424$. 